\title{
Functional gastrointestinal disorders: History taking skills in practice
}

\author{
Authors: Megan Daly ${ }^{A}$ and Natalia Zarate-Lopez ${ }^{B}$
}

This article offers a framework in history taking for functional gastrointestinal disorders (FGIDs). Clinicians rely on history taking and knowledge of the latest 'Rome IV criteria' rather than biomarkers to make a positive diagnosis of FGIDs. Improving one's history-taking skills is imperative, as early diagnosis can improve patient outcomes by avoiding over investigation and/or chronicity.

Our suggested structure for history taking adopts the biopsycho-social model of disease. We describe the assessment of gastrointestinal symptoms with open and closed questions, the importance of ruling out 'alarm' signs or symptoms, the use of a multi-system approach to identify coexisting functional disorders and eliciting patients' nutritional history. We explore the increased psychological comorbidity present in FGIDs and the significance of the social history in identify predisposing, precipitating, perpetuating and protective factors, which will ultimately guide treatment recommendations.

We believe history taking should be used to build rapport with patients while, at the same time, validating their problems and reducing stigma. Reattribution of symptoms is then achieved through education of the gut-brain axis and can be used to provide reassurance to patients at the first encounter. Success of treatment depends on engagement and acceptance of such explanations.

KEYWORDS: functional GI disorders, history taking, neurogastroenterology, bio-psycho-social, diagnosis

DOI: 10.7861/clinmed.2021-0189

\section{Introduction}

Functional gastrointestinal disorders (FGIDs) are increasingly prevalent in both primary and secondary care. Worldwide, the pooled prevalence of FGIDs is over $40 \%$. Many clinicians feel apprehensive about patients presenting with FGIDs during a busy clinic list and report leaving consultations with an unsettling feeling that something has been missed or that unnecessary investigations have been initiated. ${ }^{2}$ Such consultations are

Authors: A gastroenterology senior house officer, University College Hospital, London, UK; ${ }^{\text {B }}$ gastroenterology consultant, University College Hospital, London, UK believed to be more challenging and time consuming than those concerning organic illnesses. ${ }^{3,4}$

Clinicians regularly report that functional disorders are difficult to diagnose through history taking alone. ${ }^{5,6}$ Such reports are at odds with the general principle that history taking can provide up to $80 \%$ of information required to make an accurate diagnosis. ${ }^{7}$ Particularly, as functional gut disorders are diagnosed through criteria based on typical symptoms occurring at a particular frequency, without the need of a biomarker for establishing a positive diagnosis. ${ }^{8}$ Thus, the importance of training to improve physicians' confidence in diagnosing functional gastrointestinal (GI) symptoms and to reduce enacted stigma cannot be overstated. ${ }^{9}$ Delaying diagnosis will postpone the initiation of therapy based on the bio-psycho-social model and may lead to over-investigation. ${ }^{10,11}$ Early positive identification and diagnosis of FGIDs can improve patients' health and reduce public health costs. Here, we aim to provide guidance on history taking to facilitate a positive diagnosis of FGIDs.

\section{Rome IV classification and the multidimensional clinical profile}

FGIDs are divided into subtypes according to criteria defined by experts from around the world grouped as the Rome Foundation. ${ }^{8}$ With origins in the late 1980s, the Rome Foundation relied on the Delphi method of decision making to come up with a definition for FGIDs. Criteria have been redefined, as research on the field has emerged over the past decades. We recommend the reader familiarises themself with the latest Rome IV criteria. The Rome IV criteria defines a total of 33 adult and 20 paediatric FGIDs, summarised in Table $1 .{ }^{8}$

Diagnostic criteria for each condition are based on a combination of physical symptoms, the region of the GI tract where symptoms are considered to generate from, their frequency and duration, and the absence of alarm signs or symptoms. ${ }^{12}$ Furthermore, the Rome Foundation has created a set of validated questionnaires derived from the Rome IV criteria to primarily aid research. ${ }^{13}$

The Rome Foundation acknowledges limitations for using Rome criteria routinely in clinical practice; for example, to meet criteria for a diagnosis of irritable bowel syndrome (IBS) using Rome IV criteria, one must report symptoms of abdominal pain associated with two of three of the following: an improvement or increase in pain relating to defecation, a change in stool form and a change in stool frequency. ${ }^{8}$ Symptoms must also have both occurred more than once a week over the prior 3-month period and persisted for over 6 months. ${ }^{8}$ Patients with clinical symptoms or features fitting 
Table 1. Adult functional gastrointestinal disorders: disorders of gut-brain interaction ${ }^{8}$

\begin{tabular}{|c|c|}
\hline Location of problem & Functional gastrointestinal disorder \\
\hline Oesophageal & $\begin{array}{l}\text { Functional chest pain } \\
\text { Functional heartburn } \\
\text { Reflux hypersensitivity } \\
\text { Globus } \\
\text { Functional dysphagia }\end{array}$ \\
\hline Gastroduodenal & $\begin{array}{l}\text { Functional dyspepsia: } \\
>\text { postprandial distress syndrome } \\
>\text { epigastric pain syndrome } \\
\text { Belching disorders: } \\
>\text { excessive supragastric belching } \\
>\text { excessive gastric belching } \\
\text { Nausea and vomiting disorders: } \\
>\text { chronic nausea vomiting syndrome } \\
>\text { cyclic vomiting syndrome } \\
>\text { cannabinoid hyperemesis syndrome } \\
\text { Rumination syndrome }\end{array}$ \\
\hline Bowel & $\begin{array}{l}\text { Irritable bowel syndrome (with } \\
\text { predominant constipation, diarrhoea, } \\
\text { mixed bowel habits or unclassified) } \\
\text { Functional constipation } \\
\text { Functional diarrhoea } \\
\text { Functional abdominal bloating/distension } \\
\text { Unspecified functional bowel disorder } \\
\text { Opioid-induced constipation }\end{array}$ \\
\hline Centrally mediated & $\begin{array}{l}\text { Centrally mediated abdominal pain } \\
\text { syndrome } \\
\text { Narcotic bowel syndrome / opioid- } \\
\text { induced gastrointestinal hyperalgesia }\end{array}$ \\
\hline $\begin{array}{l}\text { Gallbladder and } \\
\text { sphincter of Oddi (SO) }\end{array}$ & $\begin{array}{l}\text { Biliary pain: } \\
>\text { functional gallbladder disorder } \\
>\text { functional biliary SO disorder } \\
\text { Functional pancreatic SO disorder }\end{array}$ \\
\hline Anorectal & $\begin{array}{l}\text { Faecal incontinence } \\
\text { Functional anorectal pain: } \\
>\text { levator ani syndrome } \\
>\text { unspecified functional anorectal pain } \\
>\text { proctalgia fugax } \\
\text { Functional defecation disorders: } \\
>\text { inadequate defecatory propulsion } \\
\text { Dyssynergic defecation }\end{array}$ \\
\hline
\end{tabular}

within a diagnosis of irritable bowel syndrome, as in other FGIDs, may not fully meet the criteria in terms of duration, impact or frequency of symptoms. Such patients may still benefit from the bio-psycho-social model of treatment for FGIDs, demonstrating the need for flexibility in the use of stringent diagnostic criteria.

In addition to establishing a positive diagnosis on the basis of history taking and well described criteria, it is recognised that subsequent management should be influenced by the impact that symptoms have on a patient's wellbeing and quality of life, and by the coexistence of extraintestinal conditions that will influence health-seeking behaviour, severity of symptoms and pharmacological approach. These factors should be elicited while taking a thorough history. Patients with mild symptoms

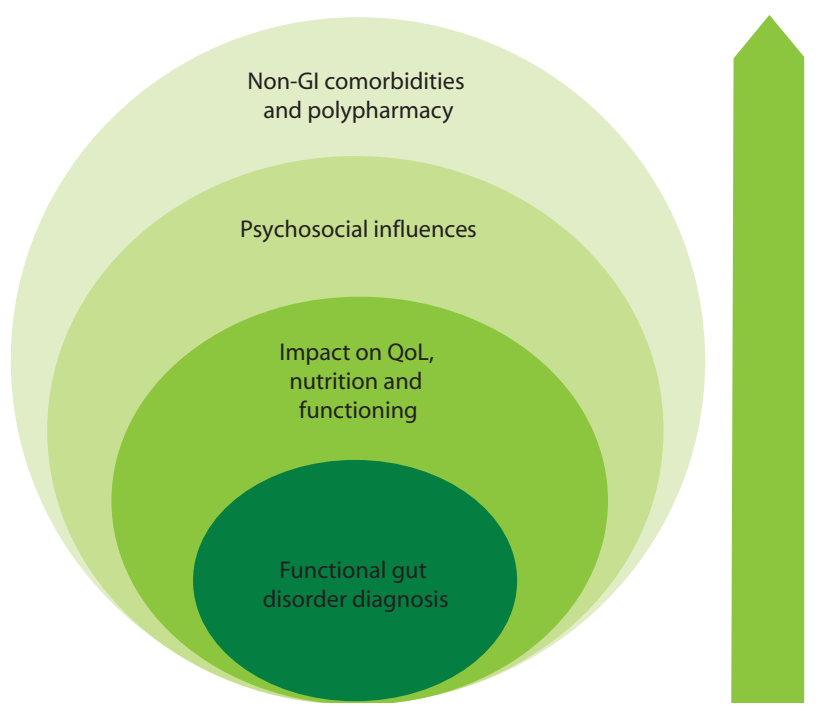

Fig 1. The Rome IV multidimensional clinical profile method. GI = gastrointestinal; QoL = quality of life.

that do not interfere with daily activities or affect nutritional status should be treated differently than patients with coexisting psychomorbidity, other functional non-GI disorders and/or polypharmacy or disordered eating. History taking should, therefore, not be limited to the assessment of GI-related symptoms.

The Rome Foundation have created an educational tool (MultiDimensional Clinical Profile) to guide clinicians managing FGIDs. ${ }^{14}$ The therapeutic strategy should be based on the severity of a patient's symptoms determined by psychological, nutritional, quality of life and pharmacological factors (Fig 1). Where once we adopted a medical model of disease, now we understand that clinicians must assess patients in the context of their unique social, psychological and medical environment. ${ }^{15}$ We will illustrate the bio-psycho-social model as the suggested framework for GI- and non-GI-related factors.

\section{Bio-psycho-social approach}

FGIDs are described as disorders of gut-brain interaction (DGBI). Applying the bio-psycho-social model to the assessment of FGIDs allows clinicians to conduct a detailed review of symptoms and their context, in an attempt both to understand the impact these have on patients' lives and to assess the psychosocial construct in which they exist. Through understanding patients' ideas, concerns and expectations, one can establish the impact of the disease and make appropriate recommendations. An overview of factors to consider in each domain is demonstrated in Fig 2.

\section{Biological}

A comprehensive biological history should include:

> history of presenting complaint

$>$ nutritional history

$>$ past medical and surgical history

$>$ drug and allergy history

$>$ family medical history. 


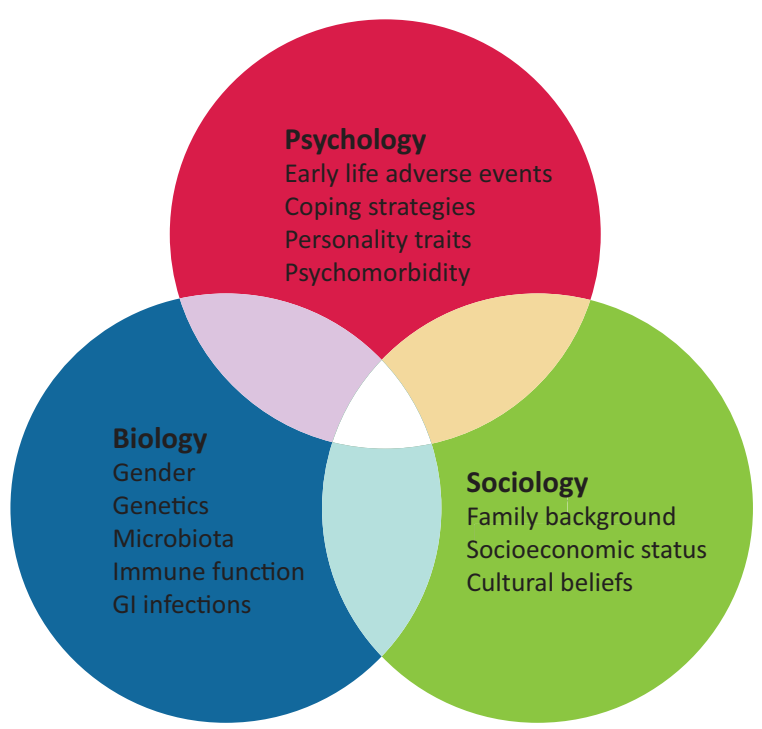

Fig 2. The bio-psycho-social model. GI = gastrointestinal.

\section{History of presenting complaint}

Common functional GI symptoms include dyspepsia, belching, nausea, pain, diarrhoea and/or constipation and continence issues. Patients with FGIDs tend to freely share information about their symptoms. Commonly, patients place attention on one aspect of their problem. ${ }^{16,17}$ Taking time to validate a patient's subjective experience is encouraged. Open questions allow patients to offload their immediate concerns, establishing the nature of their presenting complaint(s). Closed questions should then be adopted to gather more relevant information regarding presenting complaints. Examples of such open questions:

$>$ when did you last feel well

> did symptoms develop suddenly or build up gradually

$>$ can you describe in your own words how you feel

> how have things changed over time and have any patterns evolved

> have you noticed any relieving factors (for example, medications, relaxation techniques and exercise)

> has anything made things worse (for example, stress, dietary changes and time of day)

> have you recognised any associated symptoms (include multisystem approach)?

A timeline of symptoms or 'symptom diary' can help one understand how symptoms have evolved and identify precipitating or perpetuating factors. Associated symptoms are often identified given the large overlap in the diagnosis of functional disorders. ${ }^{18}$ Some examples of functional non-GI disorders are outlined in Table 2. Clinicians should consider descriptions of multiple associated symptoms and/or excessive pain or fatigue as a possible indication for a somatising disorder.

Careful questioning can determine if pain is likely to be organic or functional in nature. Functional GI pain is usually absent during the nocturnal period, constant or almost constant during the diurnal period and might be exacerbated by bowel movements in IBS or by meals in patients with functional dyspepsia. Frequently, GI-related pain coexists with gynaecological pain or other
Table 2. Examples of functional disorders per specialty

$\begin{array}{ll}\text { Specialty } & \text { Functional disorder } \\ \text { Gynaecology } & \text { Chronic pelvic pain } \\ \text { Rheumatology } & \begin{array}{l}\text { Chronic fatigue } \\ \text { Fibromyalgia }\end{array} \\ \text { Cardiology } & \text { Non-cardiac chest pain } \\ & \text { Palpitations } \\ \text { Respiratory } & \text { Hyperventilation } \\ \text { Ear, nose and throat } & \text { Dizziness } \\ \text { Urology } & \text { Painful bladder syndrome } \\ \text { Neurology } & \text { Non-epileptic seizures }\end{array}$

extra-abdominal functional pain syndromes like fibromyalgia or temporo-mandibular dysfunction. Pain in FGIDs is often described with emotional terms and the urgent and/or intense nature of the pain highlighted, while the patient might sit comfortably in the clinical room. Pain is also described as diffuse or involving different regions of the abdomen at different times, rather than being located in a particular region. Pain intensity will increase during physical examination, as patients exhibit hyperalgesia, and can be reduced by implementing distraction techniques.

Closed questioning should also be used to identify any 'red flag' features that could indicate serious underlying pathology, such as malignancy, warranting urgent referral for further investigations. Important red flag symptoms as described by the National Institute for Health and Care Excellence in their guidance for referral of suspected cancer includes weight loss, change in bowel habit, loss of appetite, upper or lower GI mass, haematemesis and unexplained rectal bleeding (Table 3). ${ }^{19}$ While alarm symptoms require urgent investigation and may indicate structural disease, a functional disorder can still be considered or revisited. ${ }^{20}$

\section{Nutritional history}

Patients with functional gut disorders frequently relate their symptoms to oral intake. Different studies have showed a relationship between the severity of the symptoms and the number of perceived food intolerances. Evolution of symptoms in response to diet is also well described, such as increased distention following fibre intake and improvement of symptoms on initiation of low-FODMAP (fermentable oligo-, di-, monosaccharides and polyols) diets. ${ }^{21,22}$ While this is a complex subject outside of the scope of this article, changes to nutritional status indicates increased severity of disorder and must be explored thoroughly. If any unhelpful behaviours or adaptations have evolved (for example, limiting or skipping meals or implementing multiple restrictive diets), then one must identify this and counsel patients accordingly in the most appropriate setting with dietitian input.

\section{Past medical and surgical history}

The prevalence of cholecystectomy, exploratory laparoscopy and appendectomy is higher in patients with FGIDs. ${ }^{23,24}$ Requesting diagnostic tests and dissatisfaction about negative investigations can lead to exploratory surgery or interventions in an attempt to alleviate patients' symptoms. Other clues to aid in the positive identification of a functional disorder include multiple and 
Table 3. National Institute for Health and Care Excellence guidance for suspected cancer referral ${ }^{19}$

$\begin{array}{ll}\text { System } & \text { Criteria } \\ \text { Gastric and oesophageal cancer } & \text { Patients with dysphagia } \\ & \text { Patients with persistent reflux and weight loss } \\ & \text { Patients with persistent reflux and associated nausea and vomiting } \\ & \text { Patients with haematemesis } \\ & \text { Patients aged over } 55 \text { years and any of upper abdominal pain with anaemia, treatment-resistant } \\ & \text { dyspepsia, raised platelets } \pm \text { nausea, and vomiting } \pm \text { weight loss } \\ & \text { Patients aged over } 40 \text { years with unexplained weight loss and abdominal pain } \\ & \text { Patients aged over } 50 \text { years with unexplained rectal bleeding } \\ \text { Colorectal cancer } & \text { Patients with iron deficiency anaemia or change in bowel habits } \\ & \text { Patients aged over } 50 \text { years with rectal bleeding and any of the following: abdominal pain, change in } \\ & \text { bowel habit, weight loss, iron deficiency anaemia } \\ & \text { Patients with a rectal or abdominal mass } \\ & \text { Patients with an unexplained anal mass or ulceration } \\ \text { Patients aged over } 40 \text { years with jaundice } & \text { Patients with weight loss and any of diarrhoea, back pain, abdominal pain, nausea and vomiting, } \\ \text { Pancreatic cancer } & \text { constipation, and new onset diabetes } \\ \text { Patients with an upper abdominal mass consistent with enlarged gall bladder or liver }\end{array}$

prolonged hospital admissions, numerous negative investigation findings and frequent attendance to the general practitioner.

\section{Drug history including allergies}

Drug history may be extensive. Some patients may be prescribed multiple analgesic medications, perhaps with pain team involvement. Others may report long-term use of anti-emetics. Polypharmacy is not infrequent in patients with a complex clinical presentation and might contribute to difficult symptom management. Asking about over-the-counter remedies could help provide further information on health behaviours. Allergy history may highlight multiple reported drug allergies or intolerances and indicate an increased susceptibility to a placebo/nocebo effect upon pharmacological interventions. ${ }^{25}$ If there are patient safety concerns, practitioners should contact local allergy teams for advice or reassurance.

\section{Family medical history}

Functional GI symptoms are multifactorial in origin. Individuals possess a degree of genetic susceptibility, which, in combination with unique environmental stressors, leads to the clinical heterogeneity observed in practice. ${ }^{26,27}$ Examples of familial environmental factors include children mimicking parental behaviour to physical symptoms leading to hypervigilance and anticipatory symptoms, particularly in relation to symptoms associated with meals. ${ }^{28}$ Asking patients about family history, and particularly prevalence of GI and psychological disorders, is relevant as themes may emerge.

\section{Psychological}

Prevalence of psychological comorbidity in FGIDs is high. ${ }^{29}$ This includes neuroticism, anxiety and somatisation, among others. ${ }^{30}$ Examples of psychological factors include emotions, personality traits, attitude and self-esteem. Clinicians can obtain relevant information by asking about past psychiatric history, as well as a patient's own ideas, concerns and expectations about their condition.
Psychological comorbidities appear to have a definite impact on patients' interpretation of symptoms, resultant health seeking and disease-related behaviours, as well as prognosis. ${ }^{31}$ Furthermore, there is ample evidence in the medical literature on the biological effect of stress and anxiety on gut sensorimotor function. ${ }^{32-34}$ Early life adverse events may impact on gut permeability and microbiota contributing to the development of GI symptoms, particularly pain and dysmotility. ${ }^{8,35}$ Childhood trauma has been shown to increase central sensitisation and pain symptoms. ${ }^{36}$ Individual events have a complex multifactorial impact on symptom generation and persistence through bidirectional communication between the brain and the gut.

\section{Social}

Environmental factors are often associated with the development of medically unexplained symptoms. Knowledge of environmental factors, in combination with a symptom diary, can help to identify patterns of behaviour and appreciate predisposing, precipitating, perpetuating and protective factors (Table 4).

Factors such as finances, relationships, employment, housing and education should be explored. A patient's upbringing can determine both how much attention is given to symptoms and how likely they are to seek medical attention. As described earlier, increased parental concern or catastrophising is thought to worsen symptoms in children with FGIDs. ${ }^{8}$ Other factors such as family dynamic, bullying, early life adverse events and major life changes may precipitate or perpetuate symptoms. Those at risk of social isolation and worsening symptoms include those with language difficulties (such as non-native speakers) and those with learning disabilities. It is vital to identify protective factors to aid the recovery process, such as good social support, long-term goals, hobbies and positive relationships. Current access to medical information through both professional and patient-led websites influences health seeking behaviour, including requests for tests and therapeutic interventions. ${ }^{37}$ The 
Table 4. Examples of predisposing, precipitating,

perpetuating and protective factors

$\begin{array}{ll}\text { Factor } & \text { Example } \\ \text { Predisposing } & \begin{array}{l}\text { Early life adverse events } \\ \text { Genetics } \\ \text { Chronic stress } \\ \text { Personality trait, anxiety, depression or neuroticism }\end{array} \\ \text { Precipitating } & \begin{array}{l}\text { Social change } \\ \text { Active medical problem }\end{array} \\ \text { Perpetuating } & \begin{array}{l}\text { Positive gain from symptom (eg attention or } \\ \text { sick role) }\end{array} \\ & \begin{array}{l}\text { Rejecting the bio-psycho-social model } \\ \text { Good support system } \\ \text { Protective }\end{array} \\ & \begin{array}{l}\text { Hobbies and interests } \\ \text { Good understanding of condition } \\ \text { Removal of stressor }\end{array}\end{array}$

impact of this environmental factor in this cohort of patients is not known.

\section{Stigma and FGIDs}

It is well described in the literature that patients with functional (when compared with organic) disorders report higher levels of stigma and this is associated with poorer patient outcomes. ${ }^{38}$ Such stigma may be due to patients' and/or professionals' lack of understanding or acceptance of the bio-psycho-social link, failure to accept or identify psychomorbidity and negative beliefs surrounding treatment options ordinarily used in treating mental health conditions.

Clinicians should be cognisant of potential stigma when taking a patient history. Some patients may feel misunderstood by health professionals due to perceived or enacted stigma occurring in previous consultations. ${ }^{9}$ When presented with functional symptoms in a consultation setting, many clinicians report a negative perception of how the clinical appointment has gone. ${ }^{2}$ By recognising and addressing feelings of frustration or uncertainty during consultations, clinicians can avoid enacted stigma towards patients.

Common challenges faced by health professionals highlighted in this article include:

> patients presenting with multiple symptoms which do not fit the professional's understanding of disease processes

> patients' anxiety regarding physical symptoms

$>$ mismatch of beliefs, expectations and objectives between the patient and the health professional

$>$ lack of patient trust in medical professionals and/or clinician perception of patient dissatisfaction

> difficulty assessing and advising on coexisting psychological or social factors due to lack of appropriate training and duration of consultation

> inadequate time allocation causing the patient to feel rushed through the consultation

$>$ patient and/or clinician concern about missing diagnosis

> patient expectation on complete relief of symptoms rather than functional improvement.

It is therefore vital that practitioners manage a patient's fears surrounding their condition, introducing educational aspects about the biological link between environmental factors like stress and symptom development, and establish trust at an early stage. Equipping healthcare professionals with strong history taking skills will help to ameliorate this barrier to successful treatment outcomes. ${ }^{38}$ This cycle of stigmatisation must be addressed if we are to reduce morbidity associated with FGIDs.

\section{Listening, validation, reattribution and reassurance}

It is important to listen to and validate patient concerns during the first encounter. In this way, patients gain insight into their condition and how it can be treated at an early stage. Patients may initially present with fixed views as to why their symptoms have developed; for example, that there is a life-threatening or sinister cause that can be identified through imaging studies. Success of certain interventions, like cognitive behaviour therapy (CBT), may be lower in patients who feel a diagnosis has been missed and psychological factors do not play a role in their condition as CBT and other psychological interventions can be highly demanding and require patient engagement. ${ }^{39}$ Addressing patients' concern is important. However, patients should be informed of the potential FGIDs diagnosis promptly and counselled that unnecessary investigations will contribute to prolonging the uncertainty about the underlying diagnosis and delay therapy initiation. ${ }^{40}$ The use of questionnaires, such as the IBS Symptom Severity Scale (IBS-SSS), are useful in validating the severity of patients' symptoms in the absence of clinical biomarkers. $^{41}$

Reattribution and reassurance should be tackled later once information gathering is complete and rapport is built. A clear and honest explanation of the multifactorial nature of functional disorders, with description of the gut-brain axis using the latest evidence, is imperative to validate a patient's symptoms within the appropriate pathophysiological framework. ${ }^{17}$ This also allows for appropriate utilisation of a multidisciplinary team (MDT) in managing patients with FGIDs and has been shown to be more cost effective while improving patient outcomes. ${ }^{42} \mathrm{~A}$ gentle holistic approach is recommended. Avoiding terminology which may increase stigma is advised; for example, when counselling patients, the term 'DGBI' is preferable to 'FGID' and 'neuromodulator' is preferable to 'anti-depressant'.

Presenting a patient with a psychological explanation for their symptoms without addressing existing fears may cause concern. Common responses from patients to such explanations may include: 'You think it is all in my head?' Clinicians should quickly assuage such concerns and provide reassurance.

\section{Example of patient-doctor interaction}

Patient: 'This nausea is unbearable, how can you say my stomach is normal?' Doctor: 'I understand that the nausea you are experiencing is severe and distressing [validation].' Then explain the gut-brain axis using current evidence [reattribution]. 'There are things that I can do and that you can do to help. I can give you medications to help your symptoms and ask for dietitian input, and you can identify triggers that we can work on (eg through CBT). All of this can improve your quality of life [reassurance].'

\section{Conclusion}

History taking for functional disorders should not be limited to the specialty symptom-based questioning, routinely used to 
explore organic health problems. Further specialty-specific training for clinicians in assessing and managing functional disorders is required. We have demonstrated how in-depth knowledge of the Rome IV criteria and structured history taking using a bio-psychosocial approach can aid the positive identification of FGIDs. This will, in turn, minimise the risk of harm to patients through overinvestigation of symptoms and facilitate early implementation of appropriate therapeutic strategies. Mild cases will benefit from reassurance while more complex ones should be managed through an MDT approach.

More time and resources must be provided to healthcare professionals in order to diagnose and treat functional disorders. The improved management of functional disorders will strengthen patient-doctor relationships, address stigma, improve patient understanding of their condition and, in turn, their compliance with treatment. Our proposed changes in training and service provision are shown to be cost effective and offer better-quality care with significant benefits for patients' quality of life.

\section{References}

1 Sperber AD, Bangdiwala SI, Drossman DA et al. Worldwide prevalence and burden of functional gastrointestinal disorders, results of Rome Foundation global study. Gastroenterology 2021;160: 99-114.e3.

2 Nimnuan C, Hotopf M, Wessely S. Medically unexplained symptoms: how often and why are they missed? QJM 2000;93:21-8.

3 Carson AJ, Stone J, Warlow C, Sharpe M. Patients whom neurologists find difficult to help. J Neurol Neurosurg Psychiatry 2004;75: 1776-8.

4 Monzoni CM, Duncan R, Grünewald R, Reuber M. How do neurologists discuss functional symptoms with their patients: A conversation analytic study. J Psychosom Res 2011;71:377-83.

5 Ford AC, Talley NJ, Veldhuyzen van Zanten SJO et al. Will the history and physical examination help establish that irritable bowel syndrome is causing this patient's lower gastrointestinal tract symptoms? JAMA 2008;300:1793-805.

6 Sood R, Gracie DJ, Law GR, Ford AC. Systematic review with metaanalysis: the accuracy of diagnosing irritable bowel syndrome with symptoms, biomarkers and/or psychological markers. Aliment Pharmacol Ther 2015:42:491-503.

7 Keifenheim KE, Teufel M, Ip J et al. Teaching history taking to medical students: a systematic review. BMC Med Educ 2015;15:159.

8 Drossman DA. Functional gastrointestinal disorders: history, pathophysiology, clinical features, and Rome IV. Gastroenterology 2016;150:P1262-79.e2.

9 Feingold JH, Drossman DA. Deconstructing stigma as a barrier to treating DGBI: Lessons for clinicians. J Neurogastroenterol Motil 2021;33:e14080

10 van Westrienen PE, Pisters MF, Veenhof C, de Wit NJ. Identification of patients with moderate medically unexplained physical symptoms in primary care with a five years follow-up. BMC Fam Pract 2019;20:66.

11 Carson AJ, Ringbauer B, Stone J, McKenzie L, Warlow C. Do medically unexplained symptoms matter? A prospective cohort study of 300 new referrals to neurology outpatient clinics. J Neurol Neurosurg Psychiatry 2000;68:207-10.

12 Palsson OS, Whitehead WE, van Tilburg MAL et al. Development and validation of the Rome IV diagnostic questionnaire for adults. Gastroenterology 2016;150:1481-91.

13 Rome Foundation. Rome IV questionnaires. Rome Foundation, 2020. Retrieved from: https://theromefoundation.org/questionnaires

14 Drossman DA, Azpiroz F, Chang L et al. Multi-Dimensional Clinical Profile (MDCP) for the functional gastrointestinal disorders. Rome Foundation, 2017.
15 Engel GL. The clinical application of the biopsychosocial model. Am J Psychiatry 1980;137:535-44.

16 Fobian AD, Elliott L. A review of functional neurological symptom disorder etiology and the integrated etiological summary model. J Psychiatry Neurosci 2019;44:8-18.

17 Stone J, Carson A, Sharpe M. Functional symptoms and signs in neurology: assessment and diagnosis. J Neurol Neurosurg Psychiatry 2005;76 (Suppl 1):i2-12.

18 Wessely S, Nimnuan C, Sharpe M. Functional somatic syndromes: one or many? Lancet 1999;354:936-9.

19 National Institute for Health and Care Excellence. Suspected cancer: recognition and referral: NICE guideline [NG12]. NICE, 2021. www.nice.org.uk/guidance/ng12

20 Longstreth GF, Thompson WG, Chey WD et al. Functional bowel disorders. Gastroenterology 2006;130(5s):1480-91.

21 Eswaran S, Muir J, Chey WD. Fiber and functional gastrointestinal disorders. Am J Gastroenterol 2013;108:718-27.

22 Gibson PR, Shepherd S]. Food choice as a key management strategy for functional gastrointestinal symptoms. Am J Gastroenterol 2012; 107:657-66; quiz 667.

23 Longstreth GF, Yao JF. Irritable bowel syndrome and surgery: A multivariable analysis. Gastroenterology 2004;126:1665-73.

24 Hasler WL, Schoenfeld P. Abdominal and pelvic surgery in patients with irritable bowel syndrome. Aliment Pharmacol Ther 2003;17:997-1005.

25 Price DD, Craggs JG, Zhou Q et al. Widespread hyperalgesia in irritable bowel syndrome is dynamically maintained by tonic visceral impulse input and placebo/nocebo factors: evidence from human psychophysics, animal models, and neuroimaging. Neuroimage 2009:47:995-1001.

26 Saito YA, Mitra N, Mayer EA. Genetic approaches to functional gastrointestinal disorders. Gastroenterology 2010;138:1276-85.

27 Camilleri M, Carlson P, McKinzie S et al. Genetic susceptibility to inflammation and colonic transit in lower functional gastrointestinal disorders: preliminary analysis. Neurogastroenterol Motil 2011;23:935-e398.

28 van Tilburg MAL, Levy RL, Walker LS et al. Psychosocial mechanisms for the transmission of somatic symptoms from parents to children. World J Gastroenterol 2015;21:5532-41.

29 Pohl D, Van Oudenhove L, Törnblom H et al. Functional dyspepsia and severity of psychologic symptoms associate with postprandial symptoms in patients with irritable bowel syndrome. Clin Gastroenterol Hepatol 2018;16:1745-53.e1.

30 Van Oudenhove L, Törnblom H, Störsrud S, Tack J, Simrén M. Depression and somatization are associated with increased postprandial symptoms in patients with irritable bowel syndrome. Gastroenterology 2016;150:866-74.

31 Stone J, LaFrance WC, Levenson JL, Sharpe M. Issues for DSM-5: conversion disorder. Am J Psychiatry 2010;167:626-7.

32 Teitelbaum AA, Gareau MG, Jury J, Yang PC, Perdue MH. Chronic peripheral administration of corticotropin-releasing factor causes colonic barrier dysfunction similar to psychological stress. Am J Physiol Gastrointest Liver Physiol 2008;295:G452-9.

33 Vicario M, Guilarte M, Alonso C et al. Chronological assessment of mast cell-mediated gut dysfunction and mucosal inflammation in a rat model of chronic psychosocial stress. Brain Behav Immun 2010;24:1166-75.

34 Alonso C, Guilarte M, Vicario M et al. Maladaptive intestinal epithelial responses to life stress may predispose healthy women to gut mucosal inflammation. Gastroenterology 2008;135:163172.e1.

35 Roelofs K, Spinhoven P, Sandijck P, Moene FC, Hoogduin KAL. The impact of early trauma and recent life-events on symptom severity in patients with conversion disorder. J Nerv Ment Dis 2005;193:508-14.

36 Sherman AL, Morris MC, Bruehl S, Westbrook TD, Walker LS Heightened temporal summation of pain in patients with 
functional gastrointestinal disorders and history of trauma. Ann Behav Med 2015;49:785-92.

37 Tan SS-L, Goonawardene N. Internet health information seeking and the patient-physician relationship: a systematic review. J Med Internet Res 2017:19:e9.

38 Hearn M, Whorwell PJ, Vasant DH. Stigma and irritable bowel syndrome: a taboo subject? Lancet Gastroenterol Hepatol 2020;5: 607-15.

39 Lee P, Zehgeer A, Ginsburg GS et al. Child and adolescent adherence with cognitive behavioral therapy for anxiety: predictors and associations with outcomes. J Clin Child Adolesc Psychol 2019;48(sup1):S215-26.

40 Spiegel BMR, Gralnek IM, Bolus R et al. Is a negative colonoscopy associated with reassurance or improved health-related quality of life in irritable bowel syndrome? Gastrointest Endosc 2005;62:892-9.
41 Francis CY, Morris ], Whorwell P]. The irritable bowel severity scoring system: a simple method of monitoring irritable bowel syndrome and its progress. Aliment Pharmacol Ther 1997;11:395-402.

42 Basnayake C, Kamm MA, Stanley A et al. Standard gastroenterologist versus multidisciplinary treatment for functional gastrointestinal disorders (MANTRA): an open-label, single-centre, randomised controlled trial. Lancet Gastroenterol Hepatol 2020;5:890-9.

Address for correspondence: Dr Megan Daly, University College Hospital, 250 Euston Road, Kings Cross, London NW1 2PG, UK.

Email: megan.daly4@nhs.net 